\title{
Tibor KOLTAY
}

\section{Data literacy in academia: Basics and pedagogical views}

\section{Introduction}

This paper, based on a non-exhaustive review of the literature addresses selected issues of a relative new complex of abilities and skills, i.e. data literacy by providing insight into its nature and the approaches to teaching in higher education.

We live in a data-intensive era, because the capacity to store massive amounts of data and forward them on high bandwidth networks generated interest in research data in the natural sciences, social sciences as well as the arts and humanities, never seen before (boyd and Crawford, 2012). The recognition of this fact motivated varied researchers, universities and different funding bodies to make efforts to encourage the openness of research data. The stakeholders of Open Data are - among others governments, multilateral organisations, journalists and the media. They come from the civil society and the private sector. Last, but not least teaching staff members, and researchers, i.e. the academic community constitute a crucial group of its stakeholders (Corrall, 2019a).

On the one hand, there remain several technological, social, organizational, economical, and legal barriers to data sharing (Sayogo \& Pardo, 2013). On the other hand, despite obstacles, we can see a shift away from a research culture, where data is viewed as a private preserve (Pryor, Jones, \& Whyte, 2013). This drive toward openness is guided among others by the principle that scholarly research does not need more data, but requires having the right data (Borgman 2015). In other words, researchers require high quality, actively curated data to work with, because data is both the raw material and the output of research (Pryor, 2012).

Research data is the output from any systematic investigation that involves observation, experiment or the testing of a hypothesis (Pryor, 2012) and it consists of "heterogeneous objects and items used and contextualized, depending on the academic discipline of origin" (Semeler, Pinto, \& Rozados 2017, p. 3). To serve as research data, little data can be just as valuable as big data, and - in many cases there is no data, because relevant data cannot be found, is not available, or does not exist at all (Borgman, 2015).

\section{Definitions}

Data literacy can be seen from different points of view, such as being related to issues of the civil society, open government, community informatics, journalism, business, and teacher education. Nonetheless, in this paper, it is approached as a "research skill for students and professionals accessing existing data sets to produce and communicate new knowledge, making scientific experiments robust and reproducible" (Corrall, 2019b, p. 2.).

One of its simple definitions says that it is a "human competence to locate, analyse, organize, present and evaluate" research data (Schneider, 2013, p. 136). A more detailed definition describes it as "a specific skill set and knowledge base, which empowers individuals to transform data into information and into actionable knowledge by enabling them to access, interpret, critically assess, manage, and ethically use data" (Koltay, 2017, p. 10).

Data literate persons know how to select and synthesize data and combine it with other information sources and prior knowledge, recognize source data value, types and formats. They determine when data is needed, then access data sources appropriate to the required information (Calzada Prado \& Marzal, 2013). 


\section{The nature of data literacy in academia}

As said above, this paper focuses on data literacy, applied in academic environments, therefore related to research data, which similarly to other types of data, needs to be managed. Research data management (RDM), consisting of a comprehensive set of activities for the organization, storage, access, and preservation of data (Semeler, Pinto, \& Rozados, 2017) is inconceivable without data literacy training, because people, who will use research data need education about how to understand, interpret, and apply what they find, and researchers are no exception from this rule. Seen from a slightly different angle, data literacy instruction is often the first step in supporting researchers (Martin, 2014), then complemented by RDM, while we should not forget about data curation that may be compared to curating a museum collection for exhibit rather than for internal storage, extended by data preservation that involves frequent validation checks and backups (Thomas \& Urban, 2018).

It is widely agreed that data literacy is in close association with data quality, which is one of the cornerstones of the data-intensive paradigm of scientific research (Koltay, 2017). Seen from a different angle, data quality analysis requires - among others - analysing the quality of the sources. The analysis of the quality of the data itself may consider accuracy, consistency, completeness, originality and the degree of timeliness of data (Daraio et al., 2016).

Data literacy is closely related to information literacy, the history of which precedes the appearance of data literacy. Nonetheless, the connection between information and data, as well as information literacy and data literacy have been underlined by Andretta et al. (2008), when they declared that presenting, evaluating, and interpreting qualitative and quantitative data is a learning outcome of information literacy.

The strongest connection between data literacy and information literacy is manifest in their attention to critical assessment, which is especially needed because of the presence of misleading or inappropriate uses of data (Carlson et al., 2011). In consequence, attention has to be paid to the version of the given dataset and the person(s) responsible for it (ACRL, 2013). Data literacy is also connected to media literacy in pointing towards "the use of tools to use and reuse content in ways not imagined by the content creator" (ACRL, 2013, p. 11).

When focusing on the academic environment, we can see that data literacy, applied to research data clearly interfaces with academic literacy, which involves the comprehension of the entire system of thinking, values, cultural identity and information flows of academia by acquiring the ability to read, interpret, and produce texts, valued in academia (Elmborg, 2006). Statistical literacy and numerical literacy (the latter also known as numeracy) are often mentioned in connection with data literacy (Schield, 2004).

\section{New views on data}

Data literacy education is deeply influenced by the changing views on the nature of data. While we traditionally have perceived data as somewhat secondary to information, because it was regarded to occupy the bottom of the data-information-knowledge-wisdom pyramid (Rowley, 2007), the growing importance of data seems to change this view. Consequently, the relationship between data and information is not seen any more as simple as it has been presented by earlier views (Makani, 2015). Liangzhi (2015) affirms this by saying that from the ontological point of view, data and information are closer to each other as both exist as signs. The fact that researchers are less interested in raw data, but give attention to its use and reuse also removes some of the differences between data and information. Therefore, research data can be recognized as information (Schneider, 2013).

Research data can be seen not just as the result of empirical work or the raw material for analysis, but also as a research object in its own right (Golub \& Hansson, 2017). Data also may be regarded as anything recordable in a semantically and pragmatically sound way (Frické, 2008), as well as a primary intellectual asset that can be subjected to peer review and other forms of quality assessment (Heidorn, 2011). 
When speaking about data literacy, we have to bring forward one of its main defining features, i.e. that it is cognate with information literacy. One of the several reasons to do this is that approaches motivating us to conceive data differently is the new definition of information literacy, which includes not only to print, but to data, images, and the spoken word (CILIP, 2018). This perception is in conformity with the idea that there are convergences between varied literacies of the information age, caused by the convergence among different forms of media and ICTs (Livingstone, van Couvering \& Thumin, 2008). Even if not directly connected to these convergences, we witness an increase in the attention towards data literacy, because it shares several features with other literacies and is especially closely connected to information literacy, reinforcing thus the close relationship between data and information (Koltay, 2015).

Speaking about data literacy in research settings requires a short excurse, where researchers' skills and abilities are examined. They are tied not only to research, but practically all kinds of literacy, involving self-management, innovative thinking and problem solving abilities (Lee, 2013).

We may add here skills that are unmistakably tied to both information and data literacy. According to Davies, Fidler and Gorbis (2011), the ideal researcher is able to filter information based on importance and use a variety of tools and techniques. Doing this is unimaginable without sense-making, since there is no serious research without the ability to determine the deeper meaning of what is being expressed at face value. Data-based reasoning has to be coupled with the ability to translate large amounts of data into abstract concepts.

As research is becoming largely determined by computing, the above abilities begin to fit into the framework of computational thinking that might be incorporated into the general thinking about scholarly research, and results in changes in its ontologies and epistemologies. This involves that mediating an object, a digital or computational device requires objects to be translated into the digital code, then being internally transformed, depending on a number of interventions, processes or filters (Berry, 2011).

\section{Approaches to teaching data literacy}

Overall, applying the principles of the Scholarship of Teaching and Learning (SoTL), the main ideas of which have been laid down by Ernest Boyer (1990) have their place here. SoTL directs the attention of teaching staff members in higher education worldwide to the need of focusing on student learning. It is geared towards understanding what is happening in the classroom and seeks ways to improve student learning (Hays \& Mallon, 2017). According to Hutchings (2000) teaching staff members should ask, what is learning is and what is happening in the classroom. They also need to find out what enables efficient student learning and should have a vision about their future classroom.

O'Brien's (2008) questions show some similarity with the above ones:

- What will my students learn and why is it worth learning?

- Who are my students?

- How do they effectively learn and what can I do to support them to learn effectively?

- How do I know if my teaching and my students' learning has been effective?

According to Kreber and Cranton (2000), SoTL involves ongoing learning about teaching and demonstrating teaching knowledge by reflecting on theory and experience-based knowledge about questions of instructional design, pedagogy, and curriculum. Besides teaching activities, it results in scholarship, published in peer-reviewed venues in order to become part of the knowledge base of teaching and learning in higher education (Richlin \& Cox, 2004).

When teaching data literacy skills to students, the overall learning outcome should be becoming data literate in the context of their subject area. Students should be able not only identify relevant data for their field of study, but understand how data is connected to the publication process. Applying critical 
thinking strategies to data and understanding the challenges of reusing data, as well as awareness of the importance of metadata and citation are crucial in this process (Duffner-Ylvestedt \& Rayner, 2016).

Data literacy education should contain the following data-related competencies:

- discovery and acquisition;

- management;

- conversion and interoperability;

- metadata;

- curation;

- re-use;

- preservation;

- analysis;

- visualization;

- ethics;

- citation (Carlson et al., 2011).

By its complexity (Silvello, 2018), the last task, i.e. data citation requires distinguished attention. Data literate researchers can efficiently retrieve data, even though data retrieval - as described by Bugaje and Chowdhury (2017) - is a less obvious task than retrieving research papers, which are available in a predominantly textual form. On the other hand, data citation is on its way to become a source of reward and acknowledgment for researchers, thus motivating them to share and publish their data (Candela et al., 2015).

Teaching data literacy should go beyond basic literacy, among others by being directed towards understanding, how to transform data into a non-raw, non-numeric representations (Bhargava, 2019).

As advised by Robinson and Bawden (2017), any data related education program could begin with considering the phenomenon of the data deluge, as well as the relation between data, information and documents. It may go so far as to examining tools for exploring data to find meaning in it, including tools of data mining.

All literacies emphasise critical appraisal in general, therefore data literacy education in particular should accentuate checking the provenance and integrity of data, giving attention to understanding factors that may impact the data, including bias, patterns, errors and omissions. It is also important to consider sampling techniques, sample selections and size, as well as survey design. We need to able to distinguish between correlation and causation, as well as understanding how variables influence each other. Having the skills of predicting, generalizing from available datasets, as well as understanding trends, and drawing inferences is indispensable (Mason, Khan, \& Smith, 2016).

Data literacy education should give distinguished attention to raising awareness of the fact that it is not exclusively about big data (Borgman, 2015). We also could count with the existence of grey data, which is useful data, produced by universities outside their research realm, but not vetted by peer review (Borgman, 2018).

Big Data is a cultural, technological, and scholarly phenomenon, characterised by the interplay of technology, analysis, and mythology (boyd \& Crawford, 2012). It is a vague concept, but - similarly literacy - it would require an understanding of "the technologies used to gather data sets, awareness of the algorithmic operations used to analyse them, and critical abilities to assess the aura of accuracy that surrounds them" (Bhargava, 2019, p. 2). Big data is big by its volume, and is defined by velocity and variety (Laney, 2001). Notwithstanding, from the point of view of data literacy education, we have to pay attention to the warning of (boyd \& Crawford, 2012), who state that big data is less about size, but capacity to search, aggregate, and cross-reference large data sets, without forgetting about the interplay of cultural, technological, and scholarly phenomena, related to it. Let me add that analysing 
small sets of data is relatively simple, relying on basic numerical literacy, while in the case of big data, machine-assisted algorithms play the main role. One of the related problems is the existence of bias toward quantitative data, leading to disrespect of qualitative methodologies. In big data environments qualitative data is analysed through a quantitative lens: looking at words counts in text, or detecting face locations in images (Bhargava, 2019).

A less recognised, but apparently useful component of data literacy education could be applying data governance principles, which are connected to data quality by being beneficial in delineating the practical domains of decision and defining accountability for decision making. Being based on standardised, repeatable processes, rules, policies, and standards, data governance's advantage to other approaches is in its transparency (Koltay, 2016).

There is also a somewhat different goal of data literacy education, i.e. fostering a culture of scholars, who are aware of their own scholarly communications' potential to become primary sources of data (Haendel et al., 2012).

When approaching these issues, we should heed the warning of Robinson (2016), who states that examining patterns and syntax and using quantitative methodology is not enough. There should be attention, given to meaning, semantics and the use of qualitative methods. In the case of research data, neglecting any of them will contribute to overly narrow approaches and lead us to building silos.

Although the variety of related terms may be sometimes disturbing, we have to mention not only data literacy and digital literacy, but digital literacy. The reason for this given - among others - by the existence of a comprehensive approach to the later. As Robinson (2016) direct our attention to an analogy here. Paul Gilster (1997) stated that digital literacy encompasses the use of printed document, because they either have been, or may become, digital. This viewpoint and helps to emphasise the importance of data. When speaking about digital literacy, we see competing views, enumerated by List (2019). Although empirical work does not support it, it is widely discussed that digital literacy is automatically acquired simply by growing up as digital natives. As mentioned above, in accordance with Gilster's view, digital literacy may be understood as an inter-related set of competencies necessary for success in the digital age.

Taking the close relationship between information literacy, digital literacy and data literacy into consideration, it seem to be expedient to suggest that - despite the obvious differences between them - constructivist theoretical and pedagogical views on information literacy can be applied to data literacy, as well. On the other hand, we must be aware that these skills remain useful, because they are easily measurable.

Most constructivist views on teaching and learning stress the experiential and empowering nature of the learning process. They are based on the idea that learning is experiential insomuch as it involves the continuous building, amending and eventually transforming of previous knowledge structures (Walton \& Cleland, 2017).

In the next part of this paper, we are going to three different approaches that are different and related to the ones, described in detail by Limberg, Sundin and Talja (2012). These approaches make use of phenomenographic and sociocultural theories, as well as discourse analytical approaches that provide a broader historical and sociological perspective to these theories.

\section{Phenomenographic approaches}

Phenomenography is a constructivist view of learning that sees learning as an activity of constructing meaning, without classifying various learning experiences as right or wrong. Therefore, phenomenographic approaches do not concentrate on a transfer of knowledge from teacher to student. They centre on the importance of understanding the learners' perspective instead (Limberg, Sundin, \& Talja, 2012). 
In the centre of phenomenographic research are participants' experiences, thus independently of the perceptions that are behind the given research, questions are asked to find out why something happens, but how and what the participants do and how they feel about it (Morrison \& Secker, 2017).

Phenomenographic studies can provide a range of meanings that information literacy and data literacy can have within any group of information users. It is able to paint a complete picture of the given knowledge domains and knowledge-based capacities (Forster, 2016).

Although originally conceived (again) for information literacy, but rooted in phenomenography-based research Bruce (1997) indicates the following activities:

- being able to use information and communication technology (ICT) for seeking and communicating information;

- seeking and finding information sources;

- executing information seeking processes;

- organising and controlling information;

- building a knowledge base in a new area of interest;

- working with knowledge and personal perspectives for novel insights;

- using information wisely for the benefit of others.

\section{The sociocultural perspective}

The sociocultural perspective pertains to the family of constructivist approaches, but instead of emphasising the role of the individual, it underlines social relations, communities, and culture (Wang, Bruce \& Hughes, 2011). It emphasises the situated nature of learning, thus focuses on the relationship between individuals and various forms of collective practices. The sociocultural perspective can be defined as ways of understanding and doing things in the world. In other words, they are based on everyday life activities (Thorne, 2013). Foundational to it is the communities of practice' concept. These communities are groups of people, which share similar goals and interests. They employ common practices, work with the same tools, and use a common language that can be defined as sets of relations among persons, activities, other communities of practice and the world. The participants in a community of practice learn not only the rules that prescribe how to perform the actual practice. Based on the community's history, assumptions, beliefs, values, and rules, the members acquire information about the legitimateness of particular practices and knowledge (Lloyd, 2010).

The process of learning involves interactions with culturally constructed tools of practice, such as objects, signs, symbols, language, and technologies, therefore the sociocultural theory focuses on toolbased information literacy practices and do this within the context of learning communities. As learning is connected to specific situations and practices, following sociocultural approaches means questioning the generic nature of learning information literacy (Limberg, Sundin, \& Talja, 2012). While accepting the broad framework of socially contextualised learning experience, they may help in developing educational practices that move the perceptions and experiences of the individual learner to the centre of educational practice (Talja \& Lloyd, 2010).

In the sociocultural perspective, information literacy is conceptualised as a collective view through a people-in-practice perspective that considers situated learning and complex social realities (Lloyd, 2012). Learning in relationship with social events and interacting with other people, objects, and events are seen in a collaborative environment.

\section{The discourse analytic perspective}

The word "discourse" may simply refer to groups of linguistic signs that expresses what has been said or written. However, but considering that social realities are formed through discourses, discourse can be understood as rule-driven productive practices for creating knowledge (Haider \& Bawden, 2007). Therefore, this perspective not only recognises language's central role to social life (Walton \& Cleland, 
2017), but allows "capturing the socially and culturally shaped ways of understanding information competencies and information practices" (Limberg, Sundin, \& Talja, 2012, 110).

There is a similarity between the sociocultural and the discourse analytic perspectives because they both regard learning as a social activity that uses tools, practices, and conditions for meaning-making (Pilerot, 2016). The discourse analytic perspective focuses on identifying broad historical literacy discourses that lead to research outcomes for understanding variation in interpretive repertoires. It demonstrates that literacies are constructed differently in different conversational contexts.

Discourse analysts study the interpretive repertoires through which people give meanings to information competences and practices, because they do not accept information competences as uncontested phenomena. They define discourses as systems of statements, i.e. sets of interlinked claims, assumptions, and meanings. The assumption is that we are users of already existing discourses, expressions, and conceptualizations, thus we accept implicit claims about the nature of information, even if we would not necessarily readily accept them as truthful or valid if we could consciously scrutinise them (Limberg, Sundin, \& Talja, 2012). However, in general, it can be said that this perspective shares several views with the phenomenographic and sociocultural approaches.

As a practical application of the discourse analytical approach, researchers - especially those, who also involved in teaching activities - should teach students not just content but also the conventions of a particular discourse community that includes the ways, how its members write, read, speak, and do research, as well as what assumptions and epistemologies underlay their arguments (Elmborg, 2006).

\section{Conclusion}

Technological advances have created opportunities and threats for the free flow of information in society, and raised awareness of the importance of information literacy (Julien \& Genuis, 2011). We witness the same development in the case of data literacy.

In general terms, data literacy is a transversal competence. Nonetheless, this paper examined it in a relatively well-defined sense, i.e. narrowing it down to its relationship to scholarly research, in particular to research data. This is the reason, why we could look at it as part of research data management and could approach it by making use of the experiences for information literacy education that already has some tradition, even if there are disputes about it. Our argument was built on this idea, whit the aim of showing selected features of this evolving field of education. Future experience and thinking will hopefully lead to fully developed theory and practice of data literacy education.

\section{References}

- ACRL (2013). Intersections of scholarly communication and information literacy: Creating strategic collaborations for a changing academic environment. Chicago, IL: Association of College and Research Libraries. http://acrl.ala.org/intersections/

- Andretta, S., Pope, A., \& Walton, G. (2008). Information literacy education in the UK: Reflections on perspectives and practical approaches of curricular integration. Communications in Information Literacy, 2(1), 36-51.

- Berry, D. (2011). The computational turn: Thinking about the digital humanities. Culture Machine, 12. http://www.culturemachine.net/index.php/cm/article/viewArticle/440.

- Bhargava, R. (2019): Data literacy. In: The International Encyclopedia of Media Literacy. Hoboken, NJ: Wiley, Paper: ieml0049 DOI: 10.1002/9781118978238.ieml0049

- Borgman, C. L. (2015): Big Data, Little Data, No Data: Scholarship in the Networked World. MIT Press, Cambridge, MA.

- Borgman, C. L. (2018). Open Data, Grey Data, and Stewardship: Universities at the Privacy Frontier. Berkeley Technology Law Journal, 3(2), 287-336. 
- boyd, d., \& Crawford, K. (2012). Critical questions for big data: Provocations for a cultural, technological, and scholarly phenomenon. Information, Communication \& Society, 15(5), 662-679.

- Boyer, E. (1990). Scholarship reconsidered: Priorities of the professoriate. San Francisco, CA: Jossey-Bass.

- Bruce, Ch. (1997). Seven Faces of Information Literacy. Blackwood: Auslib Press,

- Bugaje, M., \& Chowdhury, G. 2017. Is Data Retrieval Different from Text Retrieval? An Exploratory Study. In: International Conference on Asian Digital Libraries. Springer, Cham, pp. 99-103.

- Calzada Prado, J. C., \& Marzal, M. A. (2013). Incorporating data literacy into information literacy programs: Core competencies and contents. Libri, 63(2), 123-134.

- Candela, L., Castelli, D., Manghi, P., \& Tani, A. (2015). Data journals: A survey. Journal of the Association for Information Science and Technology, 66(9), 1747-1762.

- Carlson, J., Fosmire, M., Miller, C. C., \& Nelson, M. S. (2011). Determining data information literacy needs: A study of students and research faculty. portal: Libraries and the Academy, 11(2), 629-657.

- CILIP (2018). CILIP Definition of Information Literacy 2018, https://infolit.org.uk/ILdefinitionCILIP2018.pdf

- Corrall, S. (2019a). The Wicked Problem of Data Literacy: A Call for Action. In: LILAC: The Information Literacy Conference, April 24-26, 2019, Nottingham, UK. http://dscholarship.pitt.edu/36759/

- Corrall, S. (2019b). Repositioning Data Literacy as a Mission-Critical Competence. In: ACRL 2019: Recasting the Narrative, http://d-scholarship.pitt.edu/id/eprint/36975

- Daraio, C., Lenzerini, M., Leporelli, C., Naggar, P., Bonaccorsi, A., \& Bartolucci, A. (2016). The advantages of an Ontology-Based Data Management approach: openness, interoperability and data quality. Scientometrics, 108(1), 441-455.

- Davies, A., Fidler, D., \& Gorbis, M. (2011). Future work skills 2020. Palo Alto, CA: Institute for the Future. http://www.iftf.org/our-work/global-landscape/work/future-work-skills-2020/.

- Duffner-Ylvestedt, N., \& Rayner, J. (2016). Hooking Up Data with Literacy: Creating an Educational Framework for Uppsala University Library. Nordic Journal of Information Literacy in Higher Education-NORIL, 8(1), 38-44.

- Elmborg, J. (2006). Critical information literacy: Implications for instructional practice. Journal of Academic Librarianship, 32(2), 192-199.

- Forster, M. (2016). Phenomenography: a methodology for information literacy research. Journal of Librarianship and Information Science, 48(4), 353-362.

- Frické, M. (2008). The knowledge pyramid: a critique of the DIKW hierarchy. Journal of Information Science, 35(2), 131-142.

- Gilster, P. (1997). Digital Literacy. New York. NY: Wiley.

- Golub, K., \& Hansson, J. (2017). (Big) Data in Library and Information Science: A Brief Overview of Some Important Problem Areas. Journal of Universal Computer Science, 23(11), 1098-1108.

- Haendel, M. A., Vasilevsky, N. A., \& Wirz, J. A. (2012). Dealing with data: A case study on information and data management literacy. PLoS Biology, 10(5), e1001339.

- Haider, J., \& Bawden, D. (2007). Conceptions of "information poverty" in LIS: a discourse analysis. Journal of Documentation, 63(4), 534-557.

- Hays, L., \& Mallon, L. (2017). Keeping Up With... The Scholarship of Teaching and Learning, Association of College \& Research Libraries http://www.ala.org/acrl/publications/keeping_up_with/sotl

- Heidorn, P. B. (2011). The emerging role of libraries in data curation and e-science. Journal of Library Administration, 51(7-8), 662-672.

- Hutchings, P. (2000) Opening Lines: Approaches to the Scholarship of Teaching and Learning. Menlo Park, CA: Carnegie Publications. 
- Julien, H., \& Genuis, S. K. (2011). Librarians' experiences of the teaching role: A national survey of librarians. Library \& Information Science Research, 33(2), 103-111.

- Koltay, T. (2015). Data literacy: in search of a name and identity. Journal of Documentation, 71(2), 401-415.

- Koltay, T. (2016). Data Governance, Data Literacy and the Management of Data Quality. IFLA Journal, 42(4): 303-312.

- Koltay, T. (2017). Data literacy for researchers and data librarians. Journal of Librarianship and Information Science, 49(1) 3-4.

- Kreber, C., \& Cranton, P. A. (2000). Exploring the scholarship of teaching. The Journal of Higher Education, 71(4), 476-495.

- Laney, D. (2001). 3D data management: Controlling data volume, velocity, and variety. http://blogs.gartner.com/doug-laney/files/2012/01/ad949-3D-Data-ManagementControlling-Data-Volume -Velocity-and-Variety.pdf

- Lee, A. Y. (2013). Literacy and competencies required to participate in knowledge societies. In Conceptual relationship of information literacy and media literacy in knowledge societies. Paris: UNESCO.

- Liangzhi, Y. (2015). Back to the fundamentals again. Journal of Documentation, 71(4), 795816.

- Limberg, L., Sundin, O., \& Talja, S. (2012). Three theoretical perspectives on information literacy. Human IT: Journal for Information Technology Studies as a Human Science, 11(2), 93130.

- List, A. (2019). Defining digital literacy development: An examination of pre-service teachers' beliefs. Computers \& Education, 138, 146-158.

- Livingstone, S., van Couvering, E. J., \& Thumin, N. (2008). Converging traditions of research on media and information literacies: Disciplinary and methodological issues. In: J. Coiro, M. Knobel, C. Lankshear, \& D.J. Leu, (Eds.), Handbook of Research on New Literacies. Lawrence Erlbaum Associates, Hillsdale, NJ. pp. 13-18.

- Lloyd, A. (2010). Information literacy landscapes: Information literacy in education, workplace and everyday contexts. Oxford: Chandos.

- Lloyd, A. (2012). Information literacy as a socially enacted practice: sensitising themes for an emerging perspective of people-in-practice. Journal of Documentation, 68(6), 772-783.

- Makani, J. (2015). Knowledge management, research data management, and university scholarship: Towards an integrated institutional research data management support-system framework. VINE, 45(3), 344-359.

- Martin, E. (2014). What Is Data Literacy? Journal of eScience Librarianship 3(1), 1-2.

- Mason, J., Khan, K., \& Smith, S. 2016. Literate, numerate, discriminate-realigning 21st century skills. In: Proceedings of the 24th International Conference on Computers in Education. Asia-Pacific Society for Computers in Education. pp. 609-614.

- Morrison, C., \& Secker, J. (2017). Understanding librarians' experiences of copyright: Findings from a phenomenographic study of UK information professionals. Library Management, 38(6/7), 354-368.

- Morrison, L. \& Weech, T. (2018). Reading data: the missing literacy from LIS education. In: Petrovska, L. et al. (Eds.) The Power of Reading: Proceedings of the XXVI Bobcatsss Symposium, University of Latvia, Riga, pp. 75-80.

- O'Brien, M. (2008) Navigating the SoTL Landscape: A Compass, Map and Some Tools for Getting Starting. International Journal for the Scholarship of Teaching and Learning, 2(2), 120.

- Pilerot, O. (2016). Connections between research and practice in the information literacy narrative: A mapping of the literature and some propositions. Journal of Librarianship and Information Science, 48(4), pp. 313-321.

- Pryor, G. (2012) Why manage research data? In Pryor G (Ed.): Managing Research Data. Facet, London, pp. 1-16. 
- Pryor, G., Jones, S., \& Whyte, A. (Eds.). (2013). Delivering research data management services: Fundamentals of good practice. Facet, London.

- Richlin, L., \& Cox, M. D. (2004). Developing scholarly teaching and the scholarship of teaching and learning through faculty learning communities. New directions for teaching and learning, 2004(97), 127-135.

- Robinson, L. (2016). Between the deluge and the dark age: Perspectives on data curation. Alexandria, 26(2) 73-76.

- Robinson, L., \& Bawden, D. (2017). "The story of data" A socio-technical approach to education for the data librarian role in the CityLIS library school at City, University of London. Library Management, 38(6/7), 312-322.

- Rowley, J. (2007). The wisdom hierarchy: representations of the DIKW hierarchy. Journal of Information Science, 33(2), 163-180.

- Sayogo, D. S., \& Pardo, T. A. (2013). Exploring the determinants of scientific data sharing: Understanding the motivation to publish research data. Government Information Quarterly, 30, S19-S31.

- Schneider, R. (2013). Research data literacy. In Kurbanoglu, S. et al. (Eds.), Worldwide Commonalities and Challenges in Information Literacy Research and Practice. Springer International, Cham, pp. 134-140.

- Semeler, A. R., Pinto, A. L., \& Rozados, H. B. F. (2017). Data science in data librarianship: Core competencies of a data librarian. Journal of Librarianship and Information Science. http://journals.sagepub.com/doi/10.1177/0961000617742465

- Silvello, G. (2018). Theory and practice of data citation. In: Journal of the Association for Information Science and Technology, 69(1), 6-20.

- Talja, S., \& Lloyd, A. (2010). Integrating theories of learning, literacies and information practices. In: A. Lloyd, \& S. Talja (Eds.), Practising Information Literacy, Bringing Theories of Learning, Practice and Information Literacy Together. Cambridge: Woodhead Publishing, pp. ix-xviii.

- $\quad$ Thomas, C. V., \& Urban, R. J. (2018). What Do Data Librarians Think of the MLIS? Professionals' Perceptions of Knowledge Transfer, Trends, and Challenges. College \& Research Libraries, 79(3), 401-423.

- Wang, L., Bruce, C., \& Hughes, H. (2011). Sociocultural theories and their application in information literacy research and education. Australian Academic and Research Libraries, 42(4), pp. 296-308.

- Walton, G., \& Cleland, J. (2017). Information literacy: empowerment or reproduction in practice? A discourse analysis approach. Journal of Documentation, 73(4), 582-594. 